\title{
Fabrication of Metal-Semiconductor Interface in Porous Silicon and Its Photoelectrochemical Hydrogen Production
}

\author{
Ilwhan Oh, ${ }^{a, *}$ Joohong Kye, ${ }^{\dagger, \mathrm{a}}$ and Seongpil Hwang ${ }^{\dagger, \mathrm{a}, *}$ \\ K.A.N.C., Suwon, Gyeonggi 443-270, Korea. *E-mail: ioh0204@gmail.com \\ ${ }^{\dagger}$ Department of Chemistry, Myongji University, Yongin 449-728, Korea. *E-mail: shwang@mju.ac.kr \\ Received October 12, 2011, Accepted October 26, 2011
}

\begin{abstract}
Porous silicon with a complex network of nanopores is utilized for photoelectrochemical energy conversion. A novel electroless Pt deposition onto porous silicon is investigated in the context of photoelectrochemical hydrogen generation. The electroless Pt deposition is shown to improve the characteristics of the PS photoelectrode toward photoelectrochemical $\mathrm{H}^{+}$reduction, though excessive Pt deposition leads to decrease of photocurrent. Furthermore, it is found that a thin layer $(<10 \mu \mathrm{m})$ of porous silicon can serve as anti-reflection layer for the underlying Si substrate, improving photocurrent by reducing photon reflection at the Si/liquid interface. However, as the thickness of the porous silicon increases, the surface recombination on the dramatically increased interface area of the porous silicon begins to dominate, diminishing the photocurrent.
\end{abstract}

Key Words : Porous silicon, Electroless deposition, Photoelectrochemistry, Hydrogen evolution reaction, Solar water splitting

\section{Introduction}

Silicon is earth-abundant, relatively low-cost semiconductor material that is most widely used in current photovoltaics, with vast knowledge base and infrastructure. ${ }^{1}$ Porous silicon (PS) is nanostructured semiconductor material that is synthesized by localized anodic dissolution in HFbased electrolyte. ${ }^{2-4}$ PS exhibits complicated networks of nanometer- or even micrometer-sized vertical pores. Size, shape, and porosity of the PS depends on various experimental conditions, such as doping type and concentration, HF concentration, current density. In 1990, it was discovered that PS exhibits efficient visible photoluminescence at room temperature, ${ }^{5}$ a phenomenon that is explained by a quantum confinement effect - in the nanometer-sized wire or filament of the PS, the band gap is increased above the original Si material $(1.1 \mathrm{eV})$, enabling visible light emission. Since the discovery there had been an enormous interest in the novel material, mainly in the context of the Si-based light-emitting devices. Metal deposition onto the PS layer has been investigated, too, which could function as contact electrode. ${ }^{6}$ PS is also used in other applications, such as sensors ${ }^{2,7}$ and substrate for surface-enhanced Raman spectroscopy. ${ }^{8}$

Photoelectrochemical $\mathrm{H}_{2}$ generation at Si/electrolyte interface has been studied for decades. ${ }^{9-13}$ Hydrogen fuel produced directly from water and sunlight has been proposed as energy carrier for emission-free, sustainable future energy system. Utilizing photon energy, a photoelectrochemical cell generates $\mathrm{H}_{2}$ on cathode and $\mathrm{O}_{2}$ on anode, as described in the following half-cell reactions:

$$
2 \mathrm{H}^{+}+2 \mathrm{e}^{-} \rightarrow \mathrm{H}_{2} \text { (cathode) }
$$

${ }^{\mathrm{a}}$ These authors contributed equally to this work.

$$
\mathrm{H}_{2} \mathrm{O} \rightarrow 1 / 2 \mathrm{O}_{2}+2 \mathrm{H}^{+}+2 \mathrm{e}^{-} \text {(anode) }
$$

The Gibbs free energy change $\Delta G^{\circ}$ of the net reaction is $237 \mathrm{~kJ} / \mathrm{mol}$, or equivalently, the standard emf $\Delta E^{\mathrm{o}}$ is $-1.23 \mathrm{~V}$. As the negative emf indicates, the net reaction is energetically uphill reaction. Thus, for unassisted (no external bias) water splitting, a photovoltage of $1.23 \mathrm{~V}$ minimum needs to be supplied by photoelectrodes to drive the water splitting reaction.

Slow electrode kinetics of hydrogen evolution reaction (HER) on Si surface lead to research efforts on surface modification with electrocatalysts, such as $\mathrm{Pt}$, to facilitate HER. Fundamental problem with using the low-band-gap Si as photocathode for $\mathrm{H}_{2}$ generation is that the difference between the $\mathrm{Si}$ valence band edge and the $\mathrm{H}^{+} / \mathrm{H}_{2}$ redox level is rather small, resulting in limited photovoltage.

Here in this work, we utilize novel electroless deposition of metal onto the PS material. The deposited metal functions as electrocatalyst and the metal-impregnated PS is characterized in terms of photoelectrochemical $\mathrm{H}_{2}$ generation. Although the light-emitting characteristic of PS material has been extensible studied, there are few reports on photon-tochemical energy conversion property of PS in electrochemical environment.

\section{Experimental Section}

Fabrication of the PS Photocathode. PS layer is fabricated by galvanostatic anodization of single-crystalline bulk $\mathrm{Si}$ in HF-based electrolyte. A p-type Si (100) wafer (Wafer World, Inc.; 10 ohm-cm; B-doped) is degreased by rinsing with acetone, isopropyl alcohol, and ultrapure deionized water (DIW) in sequence. Backside ohmic contact is formed by depositing annealed $\mathrm{Al}$ ohmic layer onto the HF-treated 
$\mathrm{Si}$ wafer. Then Si sample is fitted into an O-ring sealed Teflon cell. Two-electrode configuration is used with the $\mathrm{Si}$ sample and a Pt wire as working and counter electrodes, respectively. Electric contact to the Si sample is formed by intimate contact of the backside ohmic layer to a $\mathrm{Cu}$ metal foil. Electrolyte solution is a mixture of 1 volume of $50 \% \mathrm{HF}$ and 1 volume of absolute ethanol. A constant current density of $30 \mathrm{~mA} / \mathrm{cm}^{2}$ is applied for $3 \mathrm{~min}$ and the resulting potential is $\sim 0.6 \mathrm{~V}$ initially and slowly increases to $\sim 0.7 \mathrm{~V}$ over time. $\mathrm{H}_{2}$ bubble is observed on the Si surface during the anodization. After the PS formation is completed, the Si sample is thoroughly rinsed with ethanol and DIW in sequence. Care is taken not to damage the PS layer by aggressive spraying or drying. The freshly formed PS layer shows yellowish brown color.

In order to impregnate the PS layer with Pt electrocatalyst, the PS sample is immersed into a solution of $0.4 \mathrm{M} \mathrm{HF}$ and 1 $\mathrm{mM} \mathrm{K}_{2} \mathrm{PtCl}_{6}$. After immersion for a designated time, the PS sample is thoroughly rinsed with DIW. After Pt impregnation, the originally hydrophobic PS surface becomes hydrophilic, evidenced by containment of water droplet on the PS layer area. A water droplet on the PS layer is maintained during handling the PS sample, which seems to prevent oxide formation in the ambient environment.

Photoelectrochemical Measurements. For photoelectrochemical measurements, a larger O-ring sealed Teflon cell is used that can accommodate a three-electrode configuration and secure a light path to the Si/electrolyte interface. Backside ohmic metal is electrically connected to a Cu metal foil. The front side of the Si sample is pressed and sealed with a Teflon O-ring, by which the projected electrode area is defined $\left(0.286 \mathrm{~cm}^{2}\right)$. A Pt counter electrode and a standard calomel reference electrode (SCE) are used. For illumination source, a halogen lamp is used, the intensity of which is controlled by the distance between the lamp and the photoelectrochemical cell. A Si photodiode (Hamamatus; model S2386-18 K) is used for intensity calibration. All glassware is thoroughly cleaned in an oxidizing bath (Nochromix, Godax Laboratories, Inc.) and rinsed with ultrapure water prior to use. Electrolyte solution is prepared by adding concentrated $\mathrm{H}_{2} \mathrm{SO}_{4}$ (Aldrich) into $0.5 \mathrm{M} \mathrm{K}_{2} \mathrm{SO}_{4}$ along with $\mathrm{pH}$ measurement. All chemicals are used as received. All measurements are conducted in three-electrode configuration using a $\mathrm{CHI} 660 \mathrm{D}$ potentiostat.

\section{Results and Discussion}

Figure 1 shows SEM micrographs of PS layers fabricated by electrochemical anodization. PS layer is fabricated on single-crystalline p-type $\mathrm{Si}(100)$ (resistivity $\sim 10 \Omega \cdot \mathrm{cm}$; Borondoped). Figure 1(a) is a SEM profile view the PS layer after anodization in $1: 1(\mathrm{v} / \mathrm{v})$ mixture of $50 \% \mathrm{HF}$ and ethanol for 3 min. A clear boundary between the PS layer and the underlying Si substrate is observed. The thickness of the PS layer is $3.9 \mu \mathrm{m}$ after etching for $3 \mathrm{~min}$, which is in good agreement with previous report. ${ }^{14}$ Figure 1 (b) shows a closeup view of Figure 1(a). A network of nanometer-sized pores
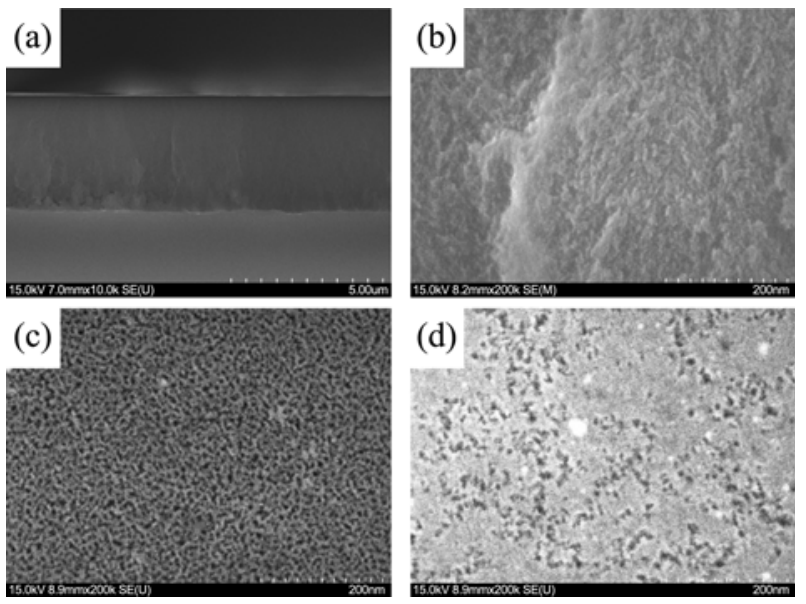

Figure 1. Scanning electron micrographs of nanoporous $\mathrm{Si}$, which is synthesized by electrochemical anodization of bulk crystalline ptype (100)-Si (10 $\Omega$-cm; B-doped) at constant current density of 30 $\mathrm{mA} / \mathrm{cm}^{2}$ for $3 \mathrm{~min}$ in 1:1 $\mathrm{HF}+$ ethanol. (a) A profile view of the nanoporous $\mathrm{Si}$ layer formed on $\mathrm{Si}$ substrate. A clear boundary between the nanoporous Si layer and the underlying Si substrate can be seen. (b) Closed-up of the profile view in (a). (c) Top view of the nanoporous $\mathrm{Si}$ showing $\sim 5 \mathrm{~nm}$ nanopores. (d) After the nanoporous $\mathrm{Si}$ is impregnated with $\mathrm{Pt}$ nanoparticles that serve as electrocatalysts for the electrode reaction.

can be seen. In Figure 1(c) is shown the top-view of the same PS layer, where a dense array of nanopore opening is observed. The diameter of the nanopores is $\sim 5 \mathrm{~nm}$, as expected for the PS formation condition used in this work.

After the PS formation is completed, Pt catalyst layer is deposited onto the PS layer. Previous methods for metal deposition onto the PS includes vacuum-based method, electrodeposition, and electroless deposition. ${ }^{6-8,15}$ Vacuumbased methods, such as sputtering and evaporation, tend to deposit metals mostly on top of the PS layer, but not inside the PS layer. Electrodeposition and electroless deposition, on the other hand, tend to deposit metals not only on the PS layer but also partly inside the PS layer, generating a gradient of metal concentration along the depth of the PS layer. Furthermore, electroless deposition is a simple and convenient method, in which metal ion in the electrolyte is deposited on the PS layer by receiving electrons from the surface hydride that has been generated during the PS formation in HF solution. The drawback of the electroless deposition is that, as the surface hydride is oxidized by metal ions, oxide layer increasingly covers the nanopore surface, limiting the extent of metal deposition. In this work, we utilized a different recipe of electroless deposition by adding HF to the deposition solution. In the presence of HF, the advantage is that electrons to reduce metal ions are generated by anodic dissolution of $\mathrm{Si}$ with $\mathrm{HF}$, preventing oxide formation. A thick layer of various metals have been deposited on Si surface using this method. ${ }^{16}$ Figure 1(D) shows a representative top-view image of PS layer after electroless deposition of $\mathrm{Pt}$ in $0.4 \mathrm{M} \mathrm{HF}$ and $1 \mathrm{mM} \mathrm{K}_{2} \mathrm{PtCl}_{6}$ for 3 min. Compared with Figure 1(c), a significant portion of nanopores on the PS layer is filled with Pt deposits. Even 


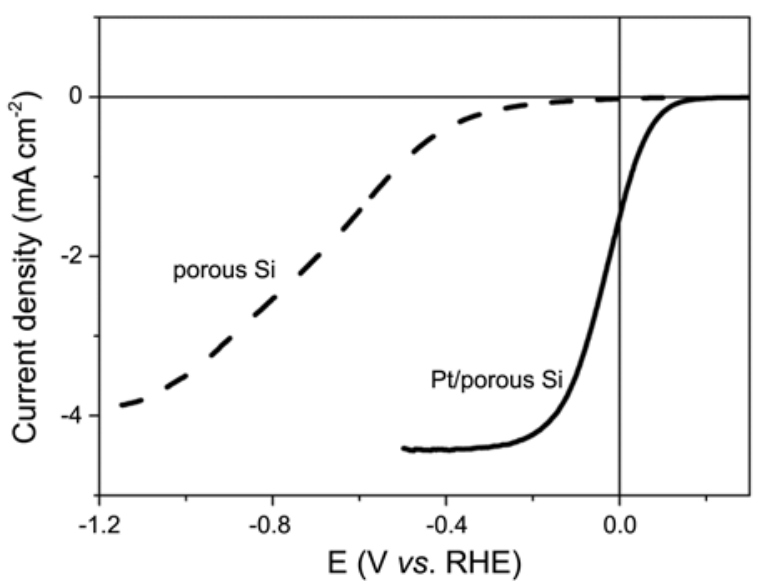

Figure 2. Photoelectrochemical $\mathrm{H}_{2}$ generation on p-type nanoporous $\mathrm{Si}$ photocathode in a solution of $\mathrm{H}_{2} \mathrm{SO}_{4}+0.5 \mathrm{M} \mathrm{K}_{2} \mathrm{SO}_{4}(\mathrm{pH}$ 1) with simulated solar radiation (intensity $=16 \mathrm{~mW} / \mathrm{cm}^{2}$ ). Bare porous $\mathrm{Si}$ (dashed line) shows significant overpotential toward $\mathrm{H}_{2}$ generation. When nanoporous $\mathrm{Si}$ is impregnated with $\mathrm{Pt}$ nanoparticle by electroless deposition, overpotential for $\mathrm{H}_{2}$ generation is significantly reduced (solid line).

Pt nanoparticles overgrown on top of the PS layer are observed. Note that not all the nanopores are filled with $\mathrm{Pt}$ deposits but a significant portion of nanopores seem to be open.

Figure 2 shows photoelectrochemical measurements of the PS layers in acidic solution of $\mathrm{H}_{2} \mathrm{SO}_{4}+0.5 \mathrm{M} \mathrm{K}_{2} \mathrm{SO}_{4}(\mathrm{pH} 1)$. During measurement, the PS layer is constantly illuminated with simulated sunlight (intensity $=16 \mathrm{~mW} / \mathrm{cm}^{2}$ ). When the thickness of the PS layer is relative small $(<30 \mu \mathrm{m})$, only a portion the incident light is absorbed by the PS layer and the rest of the incident light is absorbed by the Si substrate. ${ }^{14}$ When the PS layer and the Si substrate absorb incident photon, a minority carrier (electron for p-type $\mathrm{Si}$ ) is generated and transported along the PS skeleton. At the semiconductor/electrolyte interface, the minority carrier is transferred across the interface, reducing $\mathrm{H}^{+}$to $\mathrm{H}_{2}$. On the bare PS photoelectrode, a large overpotential is observed and the onset potential $\left(E_{\mathrm{OS}}\right)$ is measured to be $-0.1 \mathrm{~V}$. On the other hand, when the PS photocathode is impregnated with Pt electrocatalyst by the electroless deposition, the overpotential is dramatically reduced and the $E_{\mathrm{OS}}$ value is enhanced to $+0.1 \mathrm{~V}$. Note the electrode potential $(E)$ is against the reversible hydrogen electrode (RHE) and a positive photovoltage indicates a positive energy conversion of photon to $\mathrm{H}_{2}$. The enhancement of $\mathrm{H}_{2}$ generation characteristics in the presence of Pt electrocatalyst is similar to the case of planar Si photocathode ${ }^{12,17,18}$ and can be contributed to more facile $\mathrm{H}^{+}$reduction on Pt electrocatalyst than on bare PS surface. As $E$ is scanned in negative direction, a current plateau is observed. In this regime, the current is limited by incident photon intensity. The current-potential curves in Figure 2 are very reproducible over several potential cycles and for different PS samples.

Figure 3 shows the effect of the Pt electroless deposition time on photoelectrochemical $\mathrm{H}_{2}$ generation on the porous
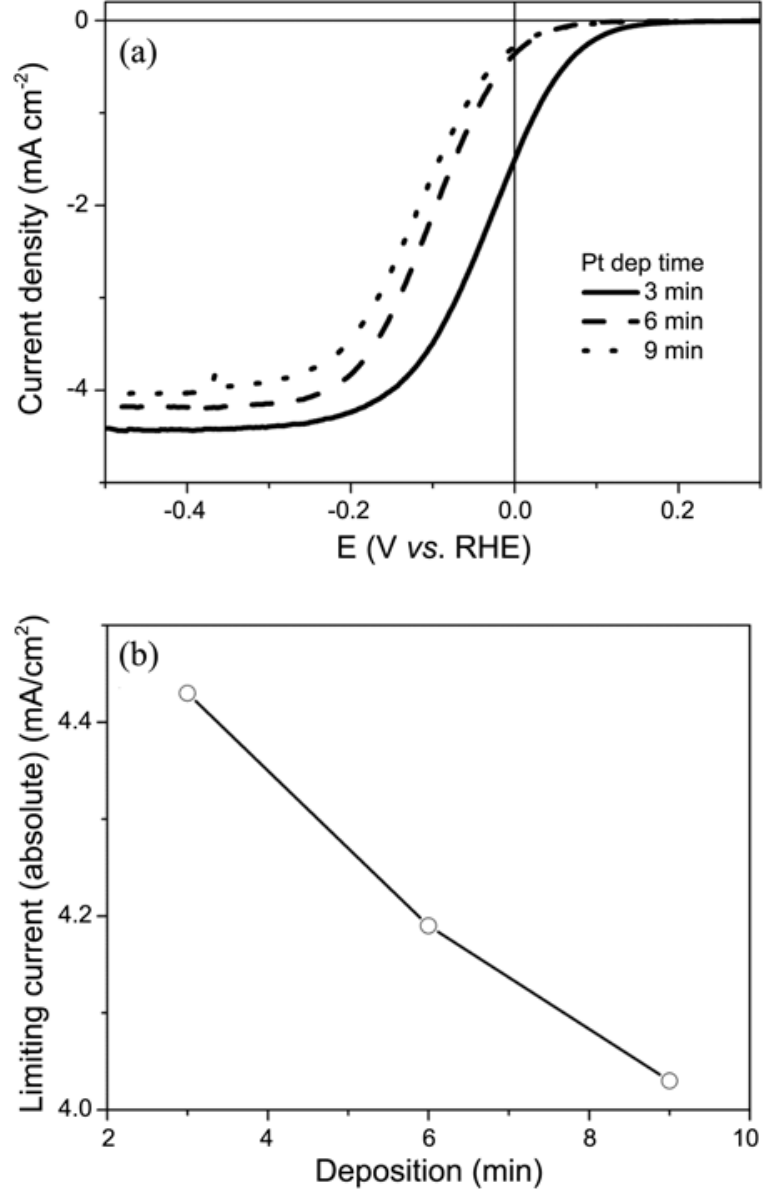

Figure 3. (a) Photoelectrochemical $\mathrm{H}_{2}$ generation on nanoporous Si photocathode (thickness $=3 \mu \mathrm{m}$ ) in a solution of $\mathrm{H}_{2} \mathrm{SO}_{4}+0.5 \mathrm{M}$ $\mathrm{K}_{2} \mathrm{SO}_{4}(\mathrm{pH}$ 1) with simulated solar radiation (intensity $=16 \mathrm{~mW} /$ $\mathrm{cm}^{2}$ ). Nanoporous $\mathrm{Si}$ is impregnated with $\mathrm{Pt}$ nanoparticle by electroless deposition for different duration. (b) Relationship between limiting current and electroless Pt deposition time.

Si (thickness $=3 \mu \mathrm{m})$. After PS formation, PS layers are impregnated with $\mathrm{Pt}$ electrocatalyst in the HF-based deposition solution for increasing duration of time: 3,6 , and $9 \mathrm{~min}$. As the deposition time is increased, the amount of $\mathrm{Pt}$ deposit will increase as well. The photoelectrochemical measurement shows that the increased $\mathrm{Pt}$ deposit has generally adverse effect on the $\mathrm{H}_{2}$ generation characteristics of the Pt/PS photocathode. $E_{\mathrm{OS}}$ is reduced from $0.2 \mathrm{~V}$ to 0.12 $\mathrm{V}$, which is attributed to slower electrode kinetics, probably due to thin oxide formation, on the porous Si surface that has been exposed to prolonged oxidation by the strongly oxidizing Pt salt. In addition, the limiting current at cathodic region diminishes as the amount of Pt deposit is increased. Figure 3(b) shows the relationship between the Pt deposition time and the limiting current density. A near-linear relation is observed, indicating that the decrease of the limiting current is most likely from the shadowing of incident light by the Pt deposit filling the nanopores of the PS layer.

Figure 4 shows the plot of thickness of the PS layer, as measured from SEM micrographs (such as from Fig. 1(a)), as function of electrochemical anodization time. In accord- 


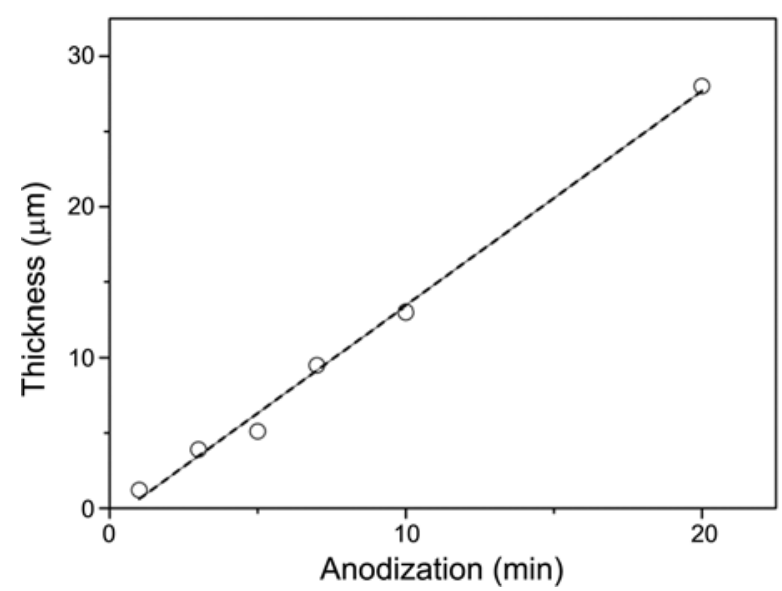

Figure 4. Thickness of the nanoporous Si layer, as measured from SEM micrographs, and electrochemical anodization time. The nanoporous $\mathrm{Si}$ layer is formed by electrochemical anodization of bulk crystalline p-type (100)-Si (10 $\Omega$-cm; B-doped) at constant current density of $30 \mathrm{~mA} / \mathrm{cm}^{2}$ in 1:1 $\mathrm{HF}+$ ethanol.

ance with previous report, ${ }^{14}$ a linear relationship between the PS layer thickness and anodization time is found. This indicates that the etch rate during PS formation is uniform regardless of the PS thickness, implying electrolyte and solvent molecules freely penetrate the whole thickness of nanopore interior, even though nanopores in the PS layer is extremely small $(\sim 5 \mathrm{~nm})$ and hydrophobic due to surface hydride.

Figure 5 shows the effect of thickness of the PS layer on photoelectrochemical $\mathrm{H}_{2}$ generation. In Figure 5(a), photoelectrochemical responses from three photocathodes with different thicknesses of the PS layer are shown: $0 \mu \mathrm{m}$ (bare Si), $5 \mu \mathrm{m}, 28 \mu \mathrm{m}$. Note that all the photoelectrodes are impregnated with $\mathrm{Pt}$ electrocatalyst by immersing the asformed PS samples into the electroless deposition solution for $3 \mathrm{~min}$. Most notably, the photocathode with 5- $\mathrm{m}$ PS layer shows higher limiting current than the bare $\mathrm{Si}$ photocathode. In Figure 5(b), the variation of limiting current is plotted as function of the PS layer thickness. The improvement of the limiting current in the presence of thin $(<5 \mu \mathrm{m})$ PS layer is probably because the PS layer serves as the anti-reflection layer for the underlying Si substrate. Due to the large difference in refractive indexes of $\mathrm{Si}$ and water, the planar Si/water interface reflects as much as $25 \%$ of the incident visible light. ${ }^{19}$ In solid-state photonic devices, various types of anti-reflection layers are utilized to reduce photon reflection at the interface. However, in the semiconductor/liquid interface, it is generally be very difficult or impossible to introduce such an anti-reflection layer because such layer would easily block interfacial electron transfer. The highly porous PS layer should have reduced density compared with bulk $\mathrm{Si}$ and function as a density-gradient layer with intermediate refractive index, significantly reducing photon reflection at the $\mathrm{Si} /$ electrolyte interface. When the PS layer thickness is increased further to $>10 \mu \mathrm{m}$, the limiting current diminishes. As shown in Figure 5(a), the limiting current for the $28-\mu \mathrm{m}$ PS layer is significantly lower
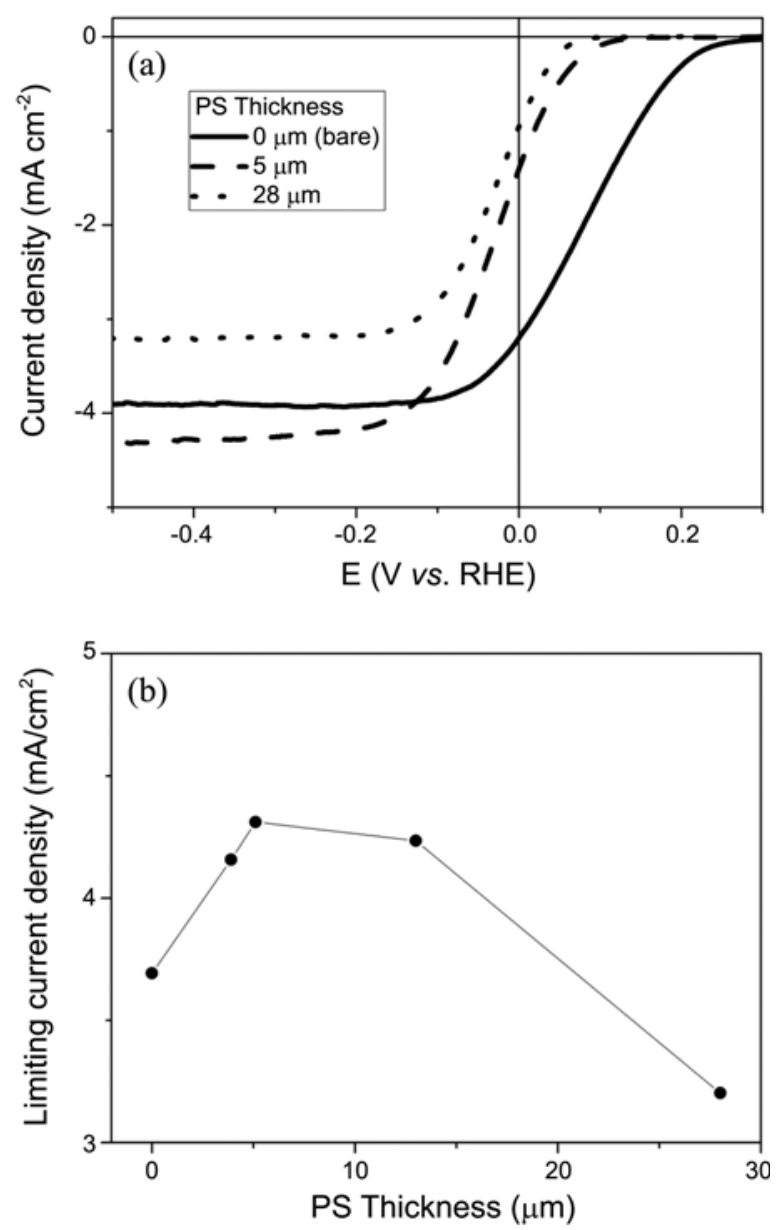

Figure 5. Photoelectrochemical $\mathrm{H}_{2}$ generation on nanoporous $\mathrm{Si}$ photocathode in a solution of $\mathrm{H}_{2} \mathrm{SO}_{4}+0.5 \mathrm{M} \mathrm{K}_{2} \mathrm{SO}_{4}(\mathrm{pH}$ 1) with simulated solar radiation (intensity $=16 \mathrm{~mW} / \mathrm{cm}^{2}$ ). (a) Different thickness of nanoporous Si layer is used. (b) Plot of the limiting current density and half-wave potential as function of thickness. In all cases, nanoporous $\mathrm{Si}$ is impregnated with $\mathrm{Pt}$ nanoparticle by electroless deposition for $3 \mathrm{~min}$.

than thinner PS layers. This phenomenon was observed previously and was attributed to surface recombination loss due to dramatically increased surface area of the thick PS layer. $^{14}$

While it was shown that, at appropriate thickness of the porous $\mathrm{Si}$, the photocurrent can be enhanced as shown in Figure 5, it should be noted that the porous Si photocathodes generally exhibit lower $E_{\mathrm{OS}}$ values than the planar $\mathrm{Si}$ counterpart, which will be a drawback in practical application. The photovoltage decrease is most likely from the dramatically increased semiconductor/electrolyte junction area. The open-circuit potential in the semiconductor/ electrolyte interface is described $\mathrm{as}^{20}$

$$
V_{\mathrm{oc}}=(k T / q) \ln \left(J_{\mathrm{ph}} / \gamma J_{\mathrm{s}}\right)
$$

where $k$ is the Boltzmann constant, $T$ is the temperature, $q$ is the electronic charge, $J_{\mathrm{ph}}$ is the photocurrent density, $\gamma$ is the surface roughness, $J_{\mathrm{s}}$ is the saturation current density. The extremely large porous $\mathrm{Si} /$ electrolyte interface area will make the $\gamma$ value for the porous Si quite large, leading to a 


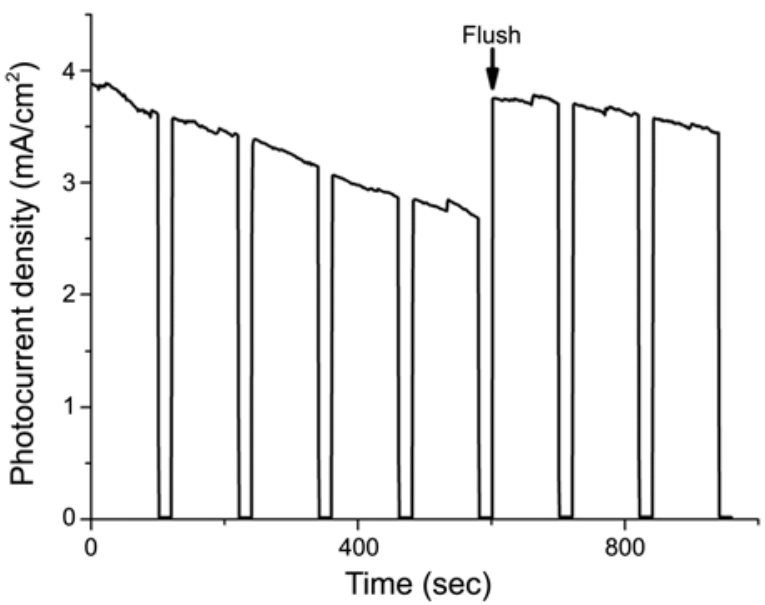

Figure 6. Current-time response of $\mathrm{H}_{2}$ generation on $\mathrm{Pt} /$ nanoporous Si photocathode illuminated with simulated sunlight (16 $\mathrm{mW} / \mathrm{cm}^{2}$ ) in a solution of $\mathrm{H}_{2} \mathrm{SO}_{4}+0.5 \mathrm{M} \mathrm{K}_{2} \mathrm{SO}_{4}(\mathrm{pH} 1)$. Electrode potential is constant at $-0.2 \mathrm{~V} v s$ RHE. The illumination is turned on for $100 \mathrm{sec}$ and off for $20 \mathrm{sec}$ repeatedly. Photocurrent slow decays over time because $\mathrm{H}_{2}$ bubbles formed on surface diminish active electrode area. At $\mathrm{t}=600 \mathrm{~s}$, the cell is flushed with fresh electrolyte solution, regenerating photocurrent level.

decrease of photovoltage. Thus, it seems that, to build a photoelectrochemical interface that exhibits maximum energy conversion, the surface roughness of Si needs to be managed so that photovoltage reduction is minimized while the benefits from nanofabricated Si interface can be harvested. Investigation in this regard is currently under way.

Figure 6 shows the long-term $\mathrm{H}_{2}$ generation on the Pt/PS photocathode illuminated with simulated sunlight (intensity $\left.=16 \mathrm{~mW} / \mathrm{cm}^{2}\right)$ in $\mathrm{H}_{2} \mathrm{SO}_{4}$ and $0.5 \mathrm{M} \mathrm{K}_{2} \mathrm{SO}_{4}(\mathrm{pH} 1)$. Electrode potential is kept constant at $-0.2 \mathrm{~V} v s$ RHE. The illumination is turned on for $100 \mathrm{sec}$ and off for $20 \mathrm{sec}$ for several cycles. A stable current output is observed initially and, on the surface of the $\mathrm{Si}$ photocathodes, it can be visually observed that $\mathrm{H}_{2}$ bubbles are initiated, grow, and set apart from the surface into solution. Intermittent current fluctuations are observed during the $100-\mathrm{sec} \mathrm{H}_{2}$ generation cycles, which are most likely from the $\mathrm{H}_{2}$ bubbles on the Si surface that mask the active electrode area in a random fashion. After 10 min of constant illumination and $\mathrm{H}_{2}$ generation, the current is degraded significantly. This is mainly due to $\mathrm{H}_{2}$ bubbles sticking on the electrode surface. At $t=600 \mathrm{~s}$, new electrolyte solution is flushed into the photoelectrochemical cell and all the bubbles on the electrode surface are removed. After the exchange, the photoelectrochemical activity of the photocathode is almost completely regenerated.

\section{Conclusion}

A novel electroless deposition of Pt electrocatalyst onto the PS layer is investigated in the context of photoelectrochemical $\mathrm{H}_{2}$ generation. It is found that electroless $\mathrm{Pt}$ deposition occur mainly on the PS pore fronts and probably inside the nanopores. The Pt impregnation of the PS layer significantly reduces the overpotential for photoelectrochemical $\mathrm{H}_{2}$ generation, due to facile electron transfer in the presence of $\mathrm{Pt}$ electrocatalyst. Excessive deposition of $\mathrm{Pt}$ is found to reduce the limiting current for $\mathrm{H}_{2}$ generation, probably by shadowing effect. Furthermore, the PS layer is found to function as anti-reflection layer and enhances the limiting current by reducing photon reflection at the $\mathrm{Si}$ / liquid interface. However, as the thickness of the PS layer increases $(>10 \mu \mathrm{m})$, surface recombination loss due to the dramatically increased surface area in the PS layer begins to be dominant, reducing the limiting current.

Acknowledgments. S. Hwang acknowledges the support from Basic Science Research Program through the National Research Foundation of Korea (NRF) funded by the Ministry of Education, Science and Technology (2011-0003612).

\section{References}

1. Luque, A.; Hegedus, S., Eds. Handbook of Photovoltaic Science and Engineering; John Wiley \& Sons: West Sussex, 2003.

2. Sailor, M. J. ACS Nano 2007, 1, 248-252.

3. Zhang, X. Journal of The Electrochemical Society 2004, 151, C69.

4. Smith, R. L.; Collins, S. D. Journal of Applied Physics 1992, 71, R1-R22.

5. Canham, L. T. Appl. Phys. Lett. 1990, 57, 1046-1048.

6. Jeske, M.; Schultze, J. W.; Thonissen, M.; Munder, H. Thin Solid Films 1995, 255, 63-66.

7. Lin, H.; Gao, T.; Fantini, J.; Sailor, M. J. Langmuir 2004, 20, 5104-5108.

8. Lin, H.; Mock, J.; Smith, D.; Gao, T.; Sailor, M. J. Journal of Physical Chemistry B 2004, 108, 11654-11659.

9. Bookbinder, D. C.; Lewis, N. S.; Bradley, M. G.; Bocarsly, A. B.; Wrighton, M. S. Journal of the American Chemical Society 1979, 101, 7721-7723.

10. Bocarsly, A. B.; Bookbinder, D. C.; Dominey, R. N.; Lewis, N. S.; Wrighton, M. S. Journal of the American Chemical Society 1980, 102, 3683-3688.

11. Bookbinder, D. C.; Bruce, J. A.; Dominey, R. N.; Lewis, N. S.; Wrighton, M. S. Proceedings of the National Academy of Sciences 1980, 77, 6280-6284.

12. Nakato, Y.; Egi, Y.; Hiramoto, M.; Tsubomura, H. Journal of Physical Chemistry 1984, 88, 4218-4222.

13. Boettcher, S. W.; Spurgeon, J. M.; Putnam, M. C.; Warren, E. L.; Turner-Evans, D. B.; Kelzenberg, M. D.; Maiolo, J. R.; Atwater, H. A.; Lewis, N. S. Science 2010, 327, 185-187.

14. Koshida, N.; Nagasu, M.; Sakusabe, T.; Kiuchi, Y. Journal of the Electrochemical Society 1985, 132, 346-349.

15. Herino, R. Materials Science and Engineering B: Solid-State Materials for Advanced Technology 2000, 69, 70-76.

16. Zhang, M.-L.; Peng, K.-Q.; Fan, X.; Jie, J.-S.; Zhang, R.-Q.; Lee, S.-T.; Wong, N.-B. Journal of Physical Chemistry C 2008, 112, 4444-4450.

17. Nakato, Y.; Hiramoto, M.; Iwakabe, Y.; Tsubomura, H. Journal of the Electrochemical Society 1985, 132, 330-334.

18. Koshida, N.; Echizenya, K. Journal of the Electrochemical Society 1991, 138, 837.

19. Oh, J.; Deutsch, T. G.; YuanH, H.-C.; Branz, O. M. Energy and Environmental Science 2011, 4, 1690.

20. Walter, M. G.; Warren, E. L.; McKone, J. R.; Boettcher, S. W.; Mi, Q.; Santori, E. A.; Lewis, N. S. Chemical Reviews 2010, 110, 6446-6473. 